\title{
The First Neurocritical Care Research Conference: A Great Starting Point
}

\author{
Jose I. Suarez $\cdot$ Peter D. LeRoux
}

Published online: 23 July 2011

(C) Springer Science+Business Media, LLC 2011

There have been significant advances in technology, informatics, understanding of disease pathophysiology, and treatments that has accelerated the evolution of Neurocritical Care during the last decade. With that comes a responsibility to answer how best to manage those patients who are admitted to Neurointensive Care Units. Many of these patients have complex disorders and pose unique management challenges. In addition, the answers from research in general ICUs do not always apply to patients with critical neurological disorders. Research, particularly randomized controlled trials (RCTs) can be a challenge in the ICU, and results may be difficult to interpret and apply to all patients. The Neurocritical Care Society recognized these dilemmas and formed the NCS Clinical Trials Committee in 2008; one of the committee's first tasks was to organize a conference to understand the current state of research in neurocritical care.

The First Neurocritical Care Research Conference was held at the St Luke's Episcopal Hospital/the Baylor College of Medicine (BCM) at the Texas Medical Center, Houston, Texas, on September 4-6, 2009. The aim of this interdisciplinary scientific gathering was to bring together scientists and physicians from diverse fields with a common interest in understanding and advancing research in neurocritical care diseases. The conference provided a forum to present and discuss the latest advances in clinical trial design, research tools, and research priorities in the

\section{J. I. Suarez (ه)}

Department of Neurology, Baylor College of Medicine,

6501 Fannin Street, NB:320 Houston, TX, USA

e-mail: jisuarez@bcm.edu

P. D. LeRoux

Department of Neurosurgery, University of Pennsylvania, Philadelphia, PA, USA field of neurocritical care. The need to create a neurocritical care research network also was discussed to facilitate collaboration and patient enrollment in clinical trials of specific neurocritical care diseases. This two-day symposium consisted of an opening reception and discussion of the present and future status of the field of neurocritical care followed by the following scientific sessions: (1) Clinical Trial Design in the Neurocritical Care Unit; (2) Research and technology in Neurocritical Care; (3) The Critical Care Research Networks Experience; and (4) Research Priorities in Neurocritical Care.

Despite being the Labor Day weekend 101 scientists and clinician-scientists converged for this venue. Attendees came from various corners of the world including the USA, Canada, the European Union, South America, Australia, and India. There was unanimous agreement that the conference was free of commercial bias. In addition, $90 \%$ of conferees agreed that the discussions were fair and balanced (based on post-conference survey). The conference was co-sponsored by the Neuroscience Program of the St Luke's Episcopal Hospital, the Baylor College of Medicine, NINDS (R13NS065494, P. I.: J. I. Suarez), and the Integra Foundation. Attendees had the opportunity to ask and discuss their views at the end of each session; these sessions were lively and interesting. There also were breakout sessions for the speakers and moderators to address and refine summary statements. There was overwhelming support for the creation of a neurocritical care research network.

This issue of Neurocritical Care contains all the summary statements that stemmed from the discussions generated during the meeting. The content of each manuscript reflects input from the speakers, session moderators, and the attendees. The names and affiliations of all the contributors are listed at the end of each article as an 
appendix. We thank all who spoke at and attended the meeting for the lively discussions and contributions that have made this issue of the journal possible. It is our hope that the publication of these summary statements will further enhance discussions about research in neurocritical care and facilitate further open and candid forums.

Acknowledgments The First Neurocritical Care Research Conference was funded by award R13NS065494 from the National Institute of Neurological Disorders and Stroke (P. I.: JI Suarez), the Integra Foundation, and the Neuroscience Center of the St Luke's Episcopal Hospital in Houston, TX, and endorsed by the Neurocritical Care Society.

Disclosures The content is solely the responsibility of the authors and does not necessarily represent the official views of the National Institute of Neurological Disorders and Stroke of the National Institutes of Health. 